\title{
Paraplegia após Revascularização Cirúrgica do Miocárdio. Relato de Caso *
}

\author{
Paraplegia after Myocardial Revascularization. Case Report
}

\author{
Caetano Nigro Neto, $T S A^{1}$, Milton Patricio Chango Iza $^{2}$, Maria Angela Tardelli, TSA ${ }^{3}$
}

\section{RESUMO}

Nigro Neto C, Iza MPC, Tardelli MA - Paraplegia após Revascularizacão Cirúrgica do Miocárdio. Relato de Caso

JUSTIFICATIVA E OBJETIVOS: Os avanços ocorridos na Anestesiologia permitiram melhores índices de segurança. Várias técnicas e agentes são utilizados visando controlar a resposta hemodinâmica e minimizar os efeitos adversos do estimulo cirúrgico em pacientes submetidos a procedimentos cardíacos.

RELATO DO CASO: Paciente de 70 anos, masculino, 1,74 m, 75 kg, ASA III, e NYHA II. Portador de dislipidemia, diabetes mellitus tipo II e hipertensão arterial controladas; tabagismo, enfermidade vascular periférica e história de infarto agudo do miocárdio há 20 anos. O paciente foi submetido a revascularização com artéria mamária interna esquerda e enxertos de safena com pinçamento intermitente da aorta em circulação extracorpórea. Durante as primeiras 24 horas na UTI apresentou eventos de instabilidade hemodinâmica, hipotensão súbita e fibrilação atrial. Após 26 horas do final do procedimento cirúrgico, o paciente estava acordado, hemodinamicamente estável e com boa dinâmica respiratória quando foi extubado. O paciente estava comunicativo, orientado, porém com imobilidade e reflexos abolidos nos membros inferiores. Na avaliação neurológica: pares de nervos cranianos sem alteração, ausência de queixa de dor de qualquer tipo da cintura pélvica para baixo, preservação da sensibilidade superficial e profunda, perfusão distal adequada sem edemas, e paraplegia flácida na região abaixo de T8. Exame de ecocardiografia sem alterações. A tomografia computadorizada da coluna lombo-sacra, não mostrou massa compressiva no espaço epidural ou adjacente.

CONCLUSÃO: A síndrome da artéria espinhal anterior, deve ser sempre considerada nos procedimentos de manipulação da aorta. A prevenção, particularmente nos pacientes de risco é necessária. $A$ tomografia computadorizada é importante para o diagnóstico diferencial e a ressonância magnética para a localização da lesão.

\footnotetext{
* Recebido (Received from) do Instituto Dante Pazzanese de Cardiologia, São Paulo, SP

1. Médico Associado da Clinica de Anestesia São Paulo; Coordenador do Serviço de Anestesia do Instituto Dante Pazzanese de Cardiologia

2. Especialista de Anestesia Cardiovascular pelo Instituto Dante Pazzanese de Cardiologia; Anestesiologista em Quito, Equador

3. Professora Adjunta da Disciplina de Anestesiologia Dor e Terapia Intensiva da Escola Paulista de Medicina da Universidade Federal de São Paulo
}

Apresentado (Submitted) em 8 de julho de 2009

Aceito (Accepted) para publicação em 24 de dezembro de 2009

Endereço para correspondência (Correspondence to):

Dr. Caetano Nigro Neto

Rua Peixoto Gomide, 502/173-B

Jardim Paulista

01409-000 São Paulo, SP

E-mail: caenigro@uol.com.br
Unitermos: CIRURGIA, Cardíaca: Revascularização do miocárdio; COMPLICAÇÕES: paraplegia; TÉCNICAS ANESTÉSICAS, Regional: raquianestesia.

\section{SUMMARY}

Nigro Neto C, Iza MPC, Tardelli MA - Paraplegia after Myocardial Revascularization. Case Report.

BACKGROUND AND OBJECTIVES: Developments in anesthesiology have improved safety indices. Several techniques and agents are used to control the hemodynamic response and minimize adverse effects triggered by surgical stimuli in patients undergoing cardiac procedures.

CASE REPORT: This is a 70 years old male patient, $1.74 \mathrm{~m}, 75 \mathrm{~kg}$, ASA III, and NYHA II. The patient had controlled dyslipedemia, type II diabetes mellitus, and hypertension; history of smoking, peripheral vascular disease, and myocardial infarction 20 years ago. The patient underwent revascularization with the left internal mammary artery and saphenous grafts with extracorporeal circulation with intermittent clamping of the aorta. During the first 24 hours in the ICU, the patient developed hemodynamic instability, sudden hypotension, and atrial fibrillation. Twenty-six hours after the end of the surgery, the patient was awake, hemodynamically stable, and with good respiratory dynamics, being extubated. The patient was talkative and oriented, but immobile and negative reflexes in the lower limbs. Neurological evaluation showed: cranial nerves without changes, no complaints of pain below the hips, preserved superficial and deep sensitivity, adequate distal perfusion without edema, and flaccid paraplegia below T8. The echocardiogram did not show any changes. CT scan of the lumbosacral spine was negative for compressive mass in the epidural space or adjacent to it.

CONCLUSION: Anterior spinal artery syndrome should be considered in procedures with manipulation of the aorta. Prevention, especially in patients at risk, is necessary. Computed tomography, for the differential diagnosis, and MRI, to localize the lesion, are important.

Keywords: ANESTHETIC TECHNIQUE, Regional: spinal anesthesia; COMPLICATIONS: paraplegia; SURGERY, cardiac: myocardial revascularization. 


\section{Paraplegia after Myocardial Revas- cularization. Case Report}

Caetano Nigro Neto, TSA, M.D.; Milton Patricio Chango Iza, M.D.; Maria Angela Tardelli, TSA, M.D.

\section{INTRODUCTION}

Over the last decades, developments in Anesthesia have resulted in a reduction in morbidity and mortality indices ${ }^{1}$. In this context, several anesthetic techniques and drugs have been used to control the hemodynamic response and minimize harmful effects triggered by the surgical stimulus in patients undergoing cardiac surgeries ${ }^{1,2}$.

Spinal blocks (intrathecal or epidural) are well-established in several surgical subspecialties. In cardiac surgeries, the association of regional block and general anesthesia is controversial, and it has been the focus of several studies in the last years. Potential benefits of regional blocks include strong postoperative analgesia, decreased response to surgical stress, and thoracic cardiac sympathectomy ${ }^{2-4}$. However, it is very difficult to determine which complications are secondary to this association, especially due to of the number and complexity of events involved in the surgical procedure.

Neurologic complications are devastating situations that can develop after cardiovascular surgery. Among them, paraplegia and paraparesis, which are rare, can be seen after several types of surgical procedures, such as repair of coarctation of the aorta, thoracotomy, lobectomy, pneumonectomy, repair of dissection of the aorta, valvular surgery, cardiac transplantation, and myocardial revascularization.

The objective of this report was to present the case of a patient who developed paraplegia after myocardial revascularization in which the association of subarachnoid opioid and general anesthesia was used.

\section{CASE REPORT}

This is a 70-year old male, $1.74 \mathrm{~m}, 75 \mathrm{~kg}$, physical status ASA III, NYHA II, with the following risk factors for coronary heart disease: dyslipidemia, type II diabetes mellitus and hypertension, all under control; smoking, peripheral vascular disease, and history of acute myocardial infarction 20 years ago.

On physical exam, the patient presented good general status, he was alert and oriented in time and space, mucous membranes were pink and hydrated, and he also showed regular nutritional status. He complained of dyspnea on medium efforts and walked with some difficulty. Neurological exam was normal. Pulmonary and cardiac auscultation showed no abnormalities, as well as abdominal examination. Lower limbs had signs of peripheral vascular disease. His blood pressure was $140 \times 80 \mathrm{mmHg}$, and the heart rhythm was regular at a rate of $80 \mathrm{bpm}$. 
His medications included: losartan, furosemide, aldactone, simvastatin, metphormin, glibenclamide, and acetyl salicylic acid. Hypoglycemic drugs were substituted by insulin 48 hours before the surgery, and acetyl salicylic acid was discontinued five days before the procedure.

Among laboratorial exams, the most important findings included: hematocrit $=34 \%$; hemoglobin $=10.9 \mathrm{mg}^{-\mathrm{dl}^{-1}}$; prothrombin time $=14$ seconds; partial activated thromboplastin time $=$ 32 seconds; platelets $=262,000 / \mathrm{mm}^{3}$; sodium $=138 \mathrm{mEq} . \mathrm{I}^{-1}$; potassium $=3.8 \mathrm{mEq} . \mathrm{I}^{-1} ;$ calcium $=0.98 \mathrm{mmol}^{-\mathrm{I}^{-1}}$; and glucose $=126 \mathrm{mg} \cdot \mathrm{dl}^{-1}$.

Echocardiography showed diffuse left ventricular hypokinesis, mitral valve reflux, and ejection fraction $40 \%$. Echo-Doppler showed $50 \%$ to $69 \%$ obstruction of the internal branch of the left carotid artery.

Cardiac catheterization showed $50 \%$ lesion in the proximal third of the circumflex artery; marginal artery with a $70 \%$ lesion in the proximal third; $60 \%$ lesion in the intermediate branch; $40 \%$ lesion in the proximal third of the anterior descending artery; diagonal artery of reduced caliber with a $40 \%$ distal lesion; dominant right coronary artery; mild increase of the left ventricle; moderate inferior-medial hypokinesis.

Chart 1 - Protocol of the Anesthesiology Department of the Dante Pazzanese Cardiology Institute

Prevention of Spinal Cord Ischemia

Preoperative identification

MRI and helical CT

of collateral branches and

Adamkiewicz artery

Sensorial and motor monitoring

Optimization of the blood flow distal to the proximal clamping site (descending aorta surgery)

Monitoring of the pressure and drainage of the CSF

Maintain the integrity of intercostal arteries

Reduce the metabolism and cellular energy requirements of the spinal cord

Avoid hypotension and hypoperfusion during anesthesia and ECC

Increase spinal Cord tolerance to ischemia

Postoperative
Perioperative monitoring of sensorial and motor evoked potentials

Gott passive bypass, transitory extra-anatomical external axillofemoral, aorto-aortic, and axillo-illiac bypass. Partial cardiopulmonary derivation for distal aortic perfusion

By inserting a catheter in the subarachnoid space

Reimplantation of intercostal arteries

Hypothermia

Maintain mean arterial pressure above $70 \mathrm{mmHg}$

Use of drugs - corticosteroids (controversial)

Postoperative assessment of sensorial and motor function after the surgery
Proposed surgical procedure: revascularization of the left internal mammary artery to the anterior descending artery, aorta to right coronary artery, and aorta to the intermediate branch with venous grafts from the anterior saphenous vein, and extracorporeal circulation with intermittent clamping of the aorta.

Monitoring included invasive blood pressure in the left femoral artery, pulse oximetry, electrocardiogram, capnography, esophageal temperature, and urine output as well as serial ABGs, peripheral venous access with a $16 \mathrm{G}$ catheter, and placement of a central line in the right subclavian vein.

For the spinal block, the $L_{3}-L_{4}$ space was punctured with a 25G Quincke needle, which required only a single attempt; $40 \mu \mathrm{g}$ of morphine and $75 \mu \mathrm{g}$ of sufentanil in NS for a total of $5 \mathrm{ml}$ were administered according to the protocols of the anesthesiology department for neuroaxis block and anticoagulation (Chart 2).

After the blockade, the patient was oxygenate with $100 \%$ oxygen by face mask, followed by induction of anesthesia with 5 $\mathrm{mg}$ of midazolam, $250 \mu \mathrm{g}$ of fentanyl, and $0.1 \mathrm{mg} \cdot \mathrm{kg}^{-1}$ of pancuronium. The patient was intubated with a \#8 ET tube with balloon, and anesthesia was maintained with $60 \%$ oxygen in a mixture with compressed air, sevoflurane with an expired fraction of up to 1 MAC (minimal alveolar concentration), besides supplemental doses of intravenous fentanyl, $2 \mu \mathrm{g} \cdot \mathrm{kg}^{-1}$ to maintain mean arterial pressure between 65 and $90 \mathrm{mmHg}$. During extracorporeal circulation (ECC), two boluses of $3 \mathrm{mg}$ of midazolam and $0.1 \mathrm{mg} \cdot \mathrm{kg}^{-1}$ of pancuronium were administered.

During the procedure, blood glucose levels were maintained between 80 and $120 \mathrm{mg}^{-\mathrm{dl}^{-1}}$ with continuous infusion of a solution containing $10 \mathrm{ml}$ of $50 \%$ glucose, $10 \mathrm{ml}$ of $19.6 \%$ potassium chloride, and $20 \mathrm{IU}$ of regular insulin, at an initial rate of $2 \mathrm{ml} . \mathrm{h}^{-1}$, which was increased by $1 \mathrm{ml} \cdot \mathrm{h}^{-1}$ when blood glucose levels rose above $120 \mathrm{mg}^{-\mathrm{dl}^{-1}}$, and intravenous bolus doses of $5 \mathrm{IU}, 10 \mathrm{IU}$, and $15 \mathrm{IU}$ of regular insulin were administered when blood glucose levels reached $200 \mathrm{mg}^{\mathrm{dl} l^{-1}}, 250 \mathrm{mg}^{\mathrm{dl}} \mathrm{d}^{-1}$, and $300 \mathrm{mg}^{\mathrm{dll}}{ }^{-1}$, respectively. The insulin infusion was interrupted when blood glucose levels were lower than $80 \mathrm{mg}^{-\mathrm{dl}^{-1}}$. Extracorporeal circulation was done with intermittent clamping of the aorta and mild hypothermia, maintaining the temperature between $33^{\circ}$ and $34^{\circ} \mathrm{C}$, with arterial flow of 40 to $60 \mathrm{ml} . \mathrm{kg}^{-1}$. $\mathrm{min}^{-1}$, and maintaining mean arterial pressure between 45 and $85 \mathrm{mmHg}$. In the case of hypertensive peak, boluses of sodium nitroprusside were administered. Intermittent clamping of the aorta, with two-minute intervals between clampings, was used during myocardial revascularization; three grafts were used: internal mammary artery to the anterior descending artery, aorta to right coronary artery, and aorta to the intermediate branch. Total perfusion time amounted to 80 minutes, and total clamping time, 57 minutes. At the end of the perfusion, dopamine $5 \mu \mathrm{g} \cdot \mathrm{kg}^{-1} \cdot \mathrm{min}^{-1}$ was administered to maintain adequate cardiac output.

The anesthetic procedure lasted 5 hours, and the surgical procedure 3 hours and 50 minutes.

Shortly after arriving at the ICU, still under the effects of anesthesia and dopamine support, arterial blood gases showed: hematocrit $=30 \%$, hemoglobin $=9.2 \mathrm{mg} \cdot \mathrm{dl}^{-1}, \mathrm{pH}=7.33, \mathrm{PCO}_{2}$ 
$=34.2, \mathrm{SatO}_{2}=99.4 \%$, base excess $=+2.6$, sodium bicarbonate $=18.9 \mathrm{mEq} . \mathrm{I}^{-1}$, sodium $=152 \mathrm{mEq} . \mathrm{I}^{-1}$, potassium $=4.6$ $\mathrm{mEq} . \mathrm{I}^{-1}$, and calcium $=0.97 \mathrm{mEq} / \mathrm{l}^{-1}$.

During the first 24 hours in the ICU, the patient developed hemodynamic instability with sudden hypotension. Dobutamine $5 \mu \mathrm{g} \cdot \mathrm{kg}^{-1} \cdot \mathrm{min}^{-1}$ was administered with the simultaneous transfusion of packed red blood cells.

During the same time, the patient developed atrial fibrillation, requiring replacement of dopamine and dobutamine by noradrenaline and amiodarone, as well as anticoagulation with the subcutaneous administration of $40 \mathrm{mg}$ of low molecular weight heparin every 12 hours.

Twenty-six hours after the end of the surgical procedure, the patient was awake, hemodynamically stable, and with good respiratory dynamics when the ET tube was removed. At that time, the patient was talkative and oriented, but he could not move the lower limbs. Neurological evaluation was as follows: cranial nerves without changes, absence of any type of pain from the pelvic girdle down, preserved superficial and deep sensitivity, deep tendon reflexes in the lower limbs were abolished, with decreased muscle tone, adequate distal perfusion without edema, and flaccid paraplegia below $\mathrm{T}_{8}$.

An echocardiogram ruled out dissection of the aorta, and a CT scan of the lumbosacral spine ruled out the presence of a compressive mass in the epidural space or adjacent to it.

\section{DISCUSSION}

Paraplegia after myocardial revascularization is a rare event. Seven cases have been reported in the MEDLINE and CINAHL ${ }^{5}$. However, the incidence after thoracoabdominal or aortoabdominal procedures ranges from 4 to $80 \%$, depending on the complexity of the procedure ${ }^{5,6}$. This type of complication is associated with several patient-, peripheral vascular disease-, and surgery-related trigger factors. Regarding the trigger factors associated with the anesthetic-surgical procedure, it is usually associated with ischemia of the spinal cord due to clamping of the aorta, reperfusion phenomena, failure to reimplant the intercostal arteries, epidural hematoma after intrathecal or epidural puncture, acute hypotension, hypoperfusion, toxic drug effects, use of the intra-aortic balloon pump, embolization, hypokalemia, trauma, and coagulopathy ${ }^{5-8}$.

Emboli resulting from the manipulation of an ascending aorta with ulcerated atherosclerotic lesions are one of the causes of ictus in patients undergoing cardiac surgeries. In patients scheduled to undergo myocardial revascularization, the identification of a mobile atheromatous plaque on transesophageal echocardiogram (TEE) increases the risk of stroke by $33 \%$ against $2.7 \%$ of those in which the same lesion is not detected. It has been suggested that the release of emboli at the moment of the injection of cardioplegic solution, aortic cannulation, the onset or end of the cardiopulmonary bypass, and clamping or unclamping of the aorta, especially the last one, are responsible for $60 \%$ of the emboli detected. Peripheral vascular disease associated with hypertension, smoking, and diffuse atheromatous plaques also represent important trigger factors, since they can lead to rupture of the plaque and the consequent embolization of the arteries of the spinal cord ${ }^{7-11}$. Hypoperfusion is the second factor that generates perioperative neurologic deficit. Although it is a constant event in those procedures, the duration of this event and prior condition of the patient are important factors for increased morbidity ${ }^{5-8}$. Elderly patients are affected more frequently, since they usually have several risk factors like: hypertension, diabetes, peripheral vascular disease, and history of myocardial infarction; those conditions favor changes in microvascular arterial perfusion and hemodynamic instability during the anesthetic-surgical procedure ${ }^{5,6,12,13}$. One should consider that the systemic inflammatory response is greater in diabetic patients with diffuse atheromatous lesions, which might lead to a higher incidence of vasoplegic syndrome associated with $\mathrm{ECC}^{14}$. All those risk factors can contribute for spinal cord ischemia, resulting in paraplegia $^{8}$. In patients with those risk factors associated with senility, mean arterial pressure should be maintained above $70 \mathrm{mmHg}$ during surgery and ECC for better microvascular perfusion of the spinal cord ${ }^{14}$. In the case presented here, the patient had several episodes of severe and prolonged hypotension during the surgery and postoperative period, which might have triggered the complications mentioned earlier.

Use of the aortocoronary bypass can also lead to a reduction in perfusion and collateral circulation of the arteries of the spinal cord. This is usually secondary to the use of the internal mammary artery ${ }^{5}$. Besides, rupture of the anastomosis of coronary grafts can also lead to systemic hypotension, which, in those patients, can cause greater spinal cord hypoperfusion. Note that the vascularization of the spinal cord varies considerably. The spinal cord has an intrinsic blood flow, in which the anterior and posterior spinal arteries, as well as their branches, are responsible for $74 \%$ of the irrigation; and an extrinsic blood flow, in which radicular arteries irrigate the nerve roots. The vertebral arteries are responsible mainly for the blood flow of the cervical, high thoracic, intercostals and lumbar regions, as well as lateral sacrum branches. The thoracolumbar segment has a significant risk of ischemia, since it receives blood from only an spinal medullar artery known as radicularis magna of Adamkiewicz. It is responsible for the vascularization of the anterior two thirds of the spinal cord and, in $75 \%$ of the individuals it originates from the left intercostal artery in the thoracic spine, in $T_{10}$ and $T_{11}$. In a small percentage of the cases, the origin of the artery radicularis magna of Adamkiewicz is more cephalad, in $\mathrm{T}_{5}$, which makes it more vulnerable to ischemic episodes in cardiac surgeries, left thoracotomy, major vascular surgeries, retroperitoneum, and left nephrectomy. Blood flow could possibly be altered by direct trauma, reduced perfusion pressure, or venous congestion. Ischemic myelopathy is the consequence of the transitory or permanent interruption of the spinal cord circulation, which is seen more often in surgical procedures, especially thoracolumbar surgery, and rarely after myocardial revascularization ${ }^{5,6,15-17}$

Other studies have reported that clinical changes secondary to a reduction of the spinal cord circulation can only be observed in the first hours or days after the procedure in $5.7 \%$ 
of the cases, establishing that the thoracolumbar segment is under a delicate and permanent perfusion balance ${ }^{8}$. Consequently, this region is extremely sensitive to ischemic lesions, reperfusion, edema, surgical trauma, and compartment injury secondary to compression, which can lead to the neurological complication known as anterior spinal artery syndrome. It is characterized by flaccid paraplegia with a level in $\mathrm{T}_{9}$, and $\mathrm{mi}-$ nimal sensorial deficit, resulting from the involvement of the blood flow in the anterior region of the spine $e^{5,6,17-20}$.

Guillian-Barré syndrome should be ruled out since it is characterized mainly by progressive muscular weakness, reduction or absence of deep tendon reflexes, ascending weakness of the pelvic and brachial muscles, and in $50 \%$ of the cases uni- or bilateral facial paralysis associated in some cases with oculomotor weakness ${ }^{21}$.

The possibility of toxic lesions caused by drugs injected inadvertently in the subarachnoid space or by contamination can also be ruled out, since this type of toxicity would be associated with the sudden onset of sensorial an motor changes, usually associated with pain ${ }^{22}$. Adhesive arachnoditis can also be ruled out since it presents with progressive hyposthesia of the lower limbs beginning days or months after the spinal block ${ }^{22,23}$.

Spinal or subarachnoid block in patients taking medications that affect systemic coagulation or who will be fully anticoagulated during the surgery, such as in surgeries with extracorporeal circulation, is a source of concern due to persistent bleeding at the puncture site. The anatomical characteristic of a closed space, of both the epidural and subdural spaces, favors the formation of a local hematoma that could compress the spinal cord and spinal roots, causing ischemic changes in the area. This complications has been reported since the early days of regional blocks ${ }^{24,25}$. A review of the literature by Vandermeulen, in $1994^{26}$, demonstrated that this is a rare complication $(1: 120,000$, with epidural block, and 1:220,000, for spinal block), and that several factors, such as the presence of bleeding disorders, comorbidities, and use of the epidural catheter during surgery, increased the risk of hematoma formation. In the years since this study, only newer drugs introduced in clinical practice caused changes in the protocol for safe spinal blocks and the care with spinal hematomas, which can be observed with the publication in 2002 of the consensus on spinal blocks and anticoagulation ${ }^{27}$.

Before the surgery, the coagulation status of the patient was stable, according to the laboratorial exams reported earlier, fulfilling the basic requirements of our protocol for spinal blocks in procedures with anticoagulation. Besides, the absence of compressive masses in the thoracolumbar CT scan ruled out the possibility of spinal compression by a hematoma ${ }^{22,23}$. The development of spontaneous hematoma was also ruled out for the same reasons ${ }^{23}$.

Spinal cord lesion causing paraplegia is a rare complication, but it should be added to the list of neurological events that could be seen after myocardial revascularization. Since this is a devastating complication, we should intensify the measures to prevent spinal cord ischemia (Chart 2). To make a differential diagnosis of spinal cord ischemia, tests, other than those mentioned here, such as myelography, electromyogra-
Chart 2 - Steps for the Prevention of Intraoperative Spinal Cord Ischemia.

\begin{tabular}{|c|c|}
\hline \multicolumn{2}{|c|}{ Protocol of General Recommendations for Neuroaxis Blocks } \\
\hline $\begin{array}{l}\text { Block is not } \\
\text { Recommended (Adults) }\end{array}$ & Block is not Recommended (Children) \\
\hline $\mathrm{aPTT}<60 \%$ & $\mathrm{aPTT}<60 \%$ \\
\hline Platelets $<100,000 / \mathrm{mm}^{3}$ & Platelets $<150,000 / \mathrm{mm}^{3}$ \\
\hline Fibrinogen $<100 \mathrm{mg}^{-\mathrm{d}^{-1}}$ & Fibrinogen $<150{\mathrm{mg} \cdot \mathrm{dl}^{-1}}^{-1}$ \\
\hline $\mathrm{PTT}>40$ seconds & $\mathrm{PTT}>40$ seconds \\
\hline PT $>14$ seconds & PT $>14$ seconds \\
\hline INR $>1.5$ & INR $>1.5$ \\
\hline \multicolumn{2}{|c|}{ Anticoagulation Rules for Neuroaxis Blocks } \\
\hline Heparin & $\begin{array}{l}\text { - Discontinue IV heparin } 4 \text { hours } \\
\text { before the block } \\
\text { - Administer heparin } 1 \text { hour after the } \\
\text { puncture } \\
\text { - Remove the catheter } 4 \text { hours after } \\
\text { the use of heparin }\end{array}$ \\
\hline $\begin{array}{l}\text { Low molecular weight } \\
\text { heparin }\end{array}$ & $\begin{array}{l}\text { Puncture or removal of the catheter } \\
12 \text { hours after the last dose of LMWH } \\
\text { - Wait } 2 \text { hours after removing of the } \\
\text { catheter to administer LMWH }\end{array}$ \\
\hline Oral anticoagulants & $\begin{array}{l}\text { - Discontinue } 7 \text { days before the spinal } \\
\text { block } \\
\text { - Remove catheter with INR }<1.5 \\
\text { - Reduce or discontinue anticoagulant } \\
\text { if INR }>3\end{array}$ \\
\hline Thrombolytic agents & $\begin{array}{l}\text { - Puncture is recommended } 21 \text { days } \\
\text { after the use of thrombolytic agents }\end{array}$ \\
\hline Antiplatelet drugs & $\begin{array}{l}\text { - Ticlopidine, discontinue } 14 \text { days } \\
\text { before } \\
\text { - Clopidogrel, discontinue } 14 \text { days } \\
\text { before } \\
\text { - Abciximab }-24-48 \text { hours before } \\
\text { - Eptifibatide and tirofiban } 4-8 \text { hours } \\
\text { before } \\
\text { - After the blockade, wait } 4 \text { weeks to } \\
\text { use GP Ilb Illa inhibitors }\end{array}$ \\
\hline
\end{tabular}

phy, and MRI of the thoracolumbar spine should have been done $^{5,6}$. Magnetic resonance imaging, a fundamental exam to establish the type and level of ischemic myelopathy, was not done in this patient. In cases of postoperative paraplegia, we recommend that all exams mentioned here should be done to determine, more precisely, the best and more adequate immediate and long-term treatment.

Although rare, anterior spinal artery syndrome should always be considered in procedures involving manipulation of the aorta and, therefore, it should be prevented, especially in patients at risk.

The CT scan is fundamental for the differential diagnosis, and the MRI is important to localize the level of the lesion.

\section{ACKNOWLEDGEMENTS}

We are grateful for the help of our collaborators: Dr. Bilal Smaili and Dr. Miguel Angel Mercado. 


\section{REFERÊNCIAS - REFERENCES}

01. Cheng DC, Karski J, Peniston C et al. - Early tracheal extubation after coronary artery bypass graft surgery reduces costs and improves resource use. A prospective, randomized, controlled trial. Anesthesiology, 1996;85:1300-1310.

02. Chaney MA - Intrathecal and epidural anesthesia and analgesia for cardiac surgery. Anesth Analg 2006;102:45-64.

03. Swenson JD, Hullander RM, Wingler $\mathrm{K}$ et al. - Early extubation after cardiac surgery using combined intrathecal sufentanil and morphine. J Cardiothorac Vasc Anesth, 1994;8:509-514.

04. Liu S, Carpenter RL, Neal JM - Epidural anesthesia and analgesia. Their role in postoperative outcome. Anesthesiology, 1995;82:1474-1506.

05. Scherr K, Urquhart G, Eichorst C et al. - Paraplegia after coronary artery bypass graft surgery: case report of a rare event. Crit Care Nurse, 2006;26:34-45.

06. Manconi M, Mondino S, Fabiane A et al. - Anterior spinal artery syndrome complicated by the ondine curse. Arch Neurol, 2003;60:17871790.

07. Rubio-Regidor M, Perez-Vela JA, Escriba-Barcena A et al. - Complicaciones neurológicas en el postoperatorio de cirugia cardiaca. Med Intensiva, 2007;31:241-50.

08. Poblete R - Mielopatias isquemicas. Rev Chil Cir, 2004;56:299-306.

09. Lacerda RC, Andréa PB, Machado Neto E et al. - Paraplegia aguda. Uma complicação rara da dissecção aórtica. Arq Bras Cardiol, 1998;70:275-278.

10. Aldrete JA, Ferrari HA - Paraplejia por anestesia epidural em um paciente con enfermedad de células falciformes y $\mathrm{SaO}_{2}$ normal. Rev Mex Anestesiol, 2004;27:107-109.

11. Silva JH, Silva ES - Anestesia em Cirurgia Vascular, em: Pita GBB, Castro AA, Buhiran E - Angiologia e Cirurgia Vascular: Guia llustrado. Maceió, UNCISAL/ECMAL \& LAVA,2003; 7-15.

12. Fujioka S, Niimi $\mathrm{Y}$, Hirata $\mathrm{K}$ et al. - Tetraplegia after coronary artery bypass grafting. Anesth Analg, 2003;97:979-80.

13. Hirose $\mathrm{H}$, Akhrass $\mathrm{R}$ - Tetraplegia after coronary artery bypass, a rare complication. Ann Thorac Cardiovasc Surg, 2005;11:270-272.

14. Mota AL, Rodrigues AJ, Evora PRB - Circulação extracorpórea em adultos no século XXI: ciência, arte ou empirismo? Rev Bras Cir Cardiovasc, 2008;23:78-92.

15. Rutter SV, Jeevananthan V, Souter R et al. - Shared spinal cord scenario: paraplegia following abdominal aortic surgery under combined general and epidural anaesthesia. Eur J Anaesthesiol, 1999;16:646-649.

16. Nandeesh BN, Mahadevan A, Santosh V et al. - Acute aortic dissection presenting as painful paraplegia. Clin Neurol Neurosurg, 2007; 109:531-534.

17. Girdauskas E, Kuntze T, Walther T et al. - Delayed paraplegia associated with vertebral necrosis after type A dissection surgery. Eur $\mathrm{J}$ Cardio-Thorac Surg, 2008;33:121-123.

18. Kakimoto M, Kawaguchi M, Sakamoto $T$ et al. - Evaluation of rapid ischemic preconditioning in a rabbit model of spinal cord ischemia. Anesthesiology, 2003;99:1112-1117.
19. Turkoz A, Gulcan O, Kizilkilic O et al. - Spinal cord ischemia caused by cardiac arrest secondary to pericardial effusion. J Cardiothorac Vasc Anesth, 2007;21:91-92.

20. Jacobs MJ, Mommertz G, Koeppel TA et al. - Surgical repair of thoracoabdominal aortic aneurysms. J Cardiovasc Surg (Torino), 2007;48:49-58.

21. Garcia Ramos GS, Cacho Diáz B - Sindrome de Guillain-Barré diagnóstico diferencial. Rev Mex Neuroci, 2005;6:448-454.

22. Canto Pastor $M$ - Anestesia regional en cirugia cardiaca. Expectativas o realidad? Rev Esp Anestesiol Reanim, 2003;50:319-325.

23. Velasco D, Buisan F - Anticoagulación, antiagregación y anestesia regional neuroaxial: riesgos y complicaciones en el paciente quirúrgico. Rev Esp Invest Quirúrgicas 2006;4:211-8.

24. Horlocker TT, Wedel DJ - Anticoagulation and neuraxial block: historical perspective, anesthetic implications, and risk management. Reg Anesth Pain Med, 1998;23(6 Suppl 2):129-134.

25. Baron HC, LaRaja RD, Rossi G et al. - Continuous epidural analgesia in the heparinized vascular surgical patient: a retrospective review of 912 patients. J Vasc Surg, 1987;6:144-146.

26. Vandermeulen EP, Van Aken $\mathrm{H}$, Vermylen $\mathrm{J}$ - Anticoagulants and spinal-epidural anesthesia. Anesth Analg, 1994;79:1165-1177.

27. Second Consensus Conference on Neuraxial Anesthesia and Anticoagulation. American Society of Regional Anesthesia and Pain 2002 April 28. Disponível em: http://www.asra.com/consensusstatements/2.html

\section{RESUMEN}

Nigro Neto C, Chango Iza MP, Tardelli MA - Paraplejia después de la Revascularización Quirúrgica del Miocardio. Relato de Caso.

JUSTIFICATIVA Y OBJETIVOS: En las últimas décadas, los avances que se han dado en anestesiología resultaron en una reducción de los indicadores de morbilidad y mortalidad. En ese contexto, varias técnicas y agentes anestésicos han sido utilizados para controlar la respuesta hemodinámica y minimizar los efectos perjudiciales provenientes del estimulo quirúrgico en pacientes sometidos a procedimientos cardíacos. En cirugía cardíaca, la asociación de la anestesia regional a la anestesia general, ha sido motivo de muchas controversias entre los anestesistas, además de haber promovido muchos estudios en los últimos años. El surgimiento de las complicaciones neurológicas, es una situación devastadora que puede ocurrir después de una cirugía cardiovascular. En este artículo, relatamos un caso de paraplejia ocurrida en un paciente de 70 años, del sexo masculino, y después de una cirugía de revascularización del miocardio añadiéndosele opioide subaracnoideo a la anestesia general. 